Discussion Paper No. 806

\title{
IMPERFECT COMPETITION, STATE TRADING AND JAPAN'S IMPORTS OF RICE
}

\author{
Donald MacLaren
}

March 2011

The Institute of Social and Economic Research Osaka University

6-1 Mihogaoka, Ibaraki, Osaka 567-0047, Japan 


\title{
Imperfect Competition, State Trading and Japan's Imports of Rice
}

\author{
Donald MacLaren* \\ Department of Economics \\ University of Melbourne \\ and \\ Visiting Foreign Scholar \\ Institute of Social and Economic Research \\ Osaka University \\ 2009
}

March 2011

\begin{abstract}
In the negotiations on agriculture in the World Trade Organization, it was asserted that an importing state trading enterprise affects the domestic market but not the international market. This claim is investigated through specifying a model of intermediaries in international trade. There are two kinds of intermediaries: first, a state trading enterprise; and second, an $n$-firm Cournot oligopsony/oligopoly that acts as the counterfactual. Using Japanese market price and quantity data for rice, and elasticity parameters drawn from the literature, the equations of the model are calibrated to these data and parameters. The resulting equations then permit the calculation of the tariff equivalence of the state trading enterprise under different assumptions about market structure, as well as the welfare effects associated with them. The equations are re-specified to model the existing import regime for rice, which is a tariff quota. The conclusions are: first, that, compared with the counterfactual, an importing state trading enterprise acts like a tariff by restricting imports; and second, the current import regime of a tariff quota causes a welfare loss compared with the counterfactual.
\end{abstract}

Key Words: state trading, Japan, rice, international intermediaries

JEL Codes: F12, F13, Q17

\footnotetext{
* The research for this paper was begun in 2009 when the author was a Visiting Foreign Scholar at the Institute of Social and Economic Research, Osaka University. He wishes to express his gratitude to Professor Yoshiyasu Ono for inviting him to visit, to the Institute for giving him the privilege of being a Visiting Foreign Scholar, and for providing such a well-supported environment in which to conduct research.
} 


\section{Imperfect Competition, State Trading and Japan's Imports of Rice}

\section{Introduction}

The rice sector of Japan's economy remains substantially influenced by government policy. Although this influence has waned somewhat in the past decade, it remains significant. A number of summary measures of the effects of that intervention are available from the OECD (2009a and 2009c) and from Honma and Hayami (2009). Using the nominal rate of assistance at undistorted prices (NRA) as their measure of support to rice producers, Honma and Hayami (Table 2.3) estimated it to be 592 per cent during the period 1985-89 and 363 per cent during 2005-07. The corresponding figures for the consumer tax equivalent (CTE) were 548.5 per cent and 348.6 per cent, respectively. A comparison of the NRA and the CTE in each of these periods suggests that most of assistance/taxation came from border policy instruments. These are very high rates of assistance to producers and taxes on consumers and, for a country that would import rice in the absence of that assistance to producers, the inference to be drawn is that there continues to be a substantial net welfare loss.

The domestic producer subsidies, other domestic instruments and the border protection that comprise these measures of assistance, reflect a changing mix of policy instruments. Whether they reflect a change in the political economy of the rice economy in Japan, is harder to judge. Over time, the settings of those instruments that have been retained have also changed, although the underlying objective seems to remain the security of supplies of rice, where security is to be interpreted to mean self-sufficiency. However, the pursuit of self-sufficiency is constrained by Japan's commitment in the World Trade Organization (WTO) to import some quantity of rice.

The set of instruments employed can be split into those that operate behind the border and those that operate at the border. ${ }^{1}$ For the purposes of this paper, only those that operate at the border are included in the modelling. In summary, imports of rice are currently subject to a tariff quota that is administered exclusively by the Ministry of Agriculture, Fisheries and Forestry (MAFF) through its Food Trade Division, the administering agency being referred to in English as the Japan Food Agency and more recently as the General Food Policy Bureau (see OECD, 2009c). ${ }^{2}$ This entity is a state trading enterprise (STE). The Understanding on the Interpretation of Article XVII of the GATT 1994 states that state trading enterprises are:

Governmental and non-governmental enterprises, including marketing boards, which have been granted exclusive or special rights or privileges, including statutory or

\footnotetext{
${ }^{1}$ The OECD has provided a description of the set of instruments (OECD, 2009b).

${ }^{2}$ Since the current import regime was introduced in FY1999, the quota has been filled each year with the exception of FY2008.
} 
constitutional powers, in the exercise of which they influence through their purchases or sales the level or direction of imports or exports. (WTO, 1995, p. 25)

It was argued in 2000 by the Japanese delegation in the negotiations on agriculture, which preceded the start of the Doha Round, that the economic effect of importing STEs is to be found only in the domestic market.

Regulations on state trading enterprises cover both export and import state trading. However, while import state trading only has an impact on the market within a particular country, export state trading affects the entire international market of a specific agricultural product. (italics in the original) (WTO, 2000, p. 18)

The corollary is that the effect of importing STEs on international markets is at most minimal, in contrast with the alleged substantial effects of exporting STEs. ${ }^{3}$ If it were the case that any country which employed an importing STE was a 'small' country, then the assertion might certainly have some validity, a priori. However, in the case of the international rice market, which is a 'thin' market with only around 5 per cent of world production being traded, Japan can hardly be treated as a small country, given the proportion of world imports of japonica rice for which Japan is responsible. This proportion is approximately 20 per cent. ${ }^{4}$ Therefore, there is a need to investigate the economic effects of the Japan Food Agency on the international rice market and to establish the extent to which the assertion by Japan's negotiators is supported by economic analysis. That is one objective in this paper. The second objective is to compare the welfare effect of the current import policy with that of unconstrained importing by private firms.

Until recently, the analytical research literature on STEs has not been particularly well developed, despite the empirical importance of STEs in certain agricultural commodity markets and in some countries. For importing countries, there is the work of Lloyd (1982), who analysed the trade effects of an STE through defining its tariff equivalence. However, the counterfactual that was used was one of perfect competition, which is, in general, inadequate. More recently, imperfectly competitive market structures have been used as the counterfactual. In a series of papers dealing with importing STEs, McCorriston and MacLaren (2005, 2008 and 2010; and in OECD 2001), have defined the counterfactual as an $n$-firm Cournot oligopsony/oligopoly, which is a more flexible counterfactual than perfect competition. By allowing $n$ to vary exogenously, the counterfactual can be made to represent any market structure between the extremes of monopsony/monopoly and perfect competition.

It is important to note that the counterfactual is a set of intermediaries and not a set of production firms. As Lahiri and Ono (1999) argued, intermediaries in international trade are an under-researched form of market structure. McCorriston and MacLaren (2005) show that

\footnotetext{
${ }^{3}$ Subsequently, it was agreed in the negotiations that, while restrictions would be placed on exporting STE, importing STE would not be subject to negotiation (see WTO, 2008, especially Appendix K).

${ }^{4}$ This figure is only approximate and was calculated from Japan's import data and world trade data for japonica rice in FAO (2010).
} 
the tariff equivalence of an importing STEs is not zero, i.e., it distorts trade relative to the imperfectly competitive counterfactual market structure. In some circumstances, it acts as a tariff and in others as in import subsidy. In the light of this finding, it is worth evaluating for Japan the claim referred to above using a similar approach as used by these authors.

The paper is organised as follows. The role of the Food Agency in Japan's import regime for rice is summarised (section 2). A model of an $n$-firm oligopoly/oligopoly is specified that is defined as the counterfactual, which procures from domestic sources and from imports and which sells to domestic consumers with the institutional reality of the tariff quota being ignored initially. To investigate the possibility that an STE distorts trade, two models of an STE are specified: the first is one in which the STE has exclusive rights of procurement and it has an objective function that is biased towards domestic producers; the second is one in which the STE is excluded from domestic procurement but has exclusive rights to import. This comparison is conducted through deriving expressions for the tariff equivalence of the STE (Section 3). Then the current institutional arrangements are modelled in which the tariff quota is taken into account (section 4). The demand and supply equations are calibrated to price and quantity data for the average of the financial years 2005-07 (section 5), thus providing some quantitative measure of the tariff equivalence and the welfare effects of the current policy regime for the rice market (section 6). The final section draws together the main findings (section 7).

\section{Japan's Import Regime for Rice}

The substantial presence of government in Japan's rice market has been reduced over time but by no means has it been entirely eliminated. ${ }^{5}$ Prior to some changes that occurred in FY2004, the principal domestic instruments had been: (i) centralised price setting (which ceased in 1995); (ii) the exclusive rights of the STE in the domestic market and over imports; (iii) an area reduction programme; (iv) government stockpiling; (v) producer and consumer subsidies; and (vi) an income stabilisation programme for rice farmers. Despite some deregulation of the domestic rice market in FY2004, the same has not been observed for imports of rice. These remain highly regulated.

Until 1995, the principal trade instrument had been the exclusive import rights for the Food Agency. Thereafter, it operated the import quota that was in place from 1995 to 1998 and, since 1999, when the quota was converted to a tariff quota, it has continued to control imports. Japan would be self-sufficient in rice at the current settings of the domestic price instruments. However, there is the WTO requirement that Japan fulfil her minimum access commitment as determined by the tariff quota. From 1995, and the introduction of the WTO

\footnotetext{
${ }^{5}$ See Honma and Hayami (2009) for an overview of the evolution of Japanese rice policy.
} 
Agreement on Agriculture, imports were subject to a target level of 4 per cent of the level of domestic consumption during the base period 1986-88 (i.e., 379,000 tonnes, milled rice equivalent). For each subsequent year, the target was to be increased by 0.8 percentage points until it reached 8 per cent by FY2000 (758,000 tonnes, milled rice equivalent). However, for FY1999, the instrument was changed to a tariff quota of 682,200 tonnes (milled rice equivalent) which, in the year FY2000, would have represented only 7.2 per cent of baseperiod consumption. Today, this quantity remains the tariff quota. The in-quota tariff is zero but the out-of-quota tariff is $¥ 341$ per kilogram. While out-of-quota imports are possible, this tariff is prohibitive (OECD, 2009b, p. 49). Imports within the quota are controlled by the Food Agency. However, the decision on how the quota is allocated across exporters is opaque.

The quota has two portions: ordinary market access (OMA) of 582,200 tonnes per year; and simultaneous buy/sell (SBS) of 100,000 tonnes per year. Under the OMA portion, the Food Agency itself does the importing and puts these imports directly into government stocks for release at a later date for consumption as table rice, for use in food processing, for use in animal feed, for use in bio-fuel production and for food aid. It has the right to impose a mark-up of up to ¥292 per kilogram. Thus, although the tariff is zero, the Food Agency will still generate revenue from imports as long as the mark-up is positive. The out-of-quota tariff is effectively $¥ 341$ per kilogram, which comprises the mark-up plus a specific tariff of $¥ 49$ per kilogram.

Under the SBS portion, private firms tender to import a specific quantity and quality of rice, notionally to sell it to the Food Agency at their own nominated price and to buy it back from the Food Agency, again at their own nominated price. The Food Agency accepts the tenders of those firms with the greatest mark-ups, subject to the quota limit of 100,000 tonnes per year. This rice remains in the hands of the private firms for sale to domestic consumers.

\section{An Import Model of State Trading}

The purpose in this section is to specify the model from which it will be possible in section 5 to obtain quantitative estimates of the tariff equivalence of the Food Agency. While it is possible to specify the model with general functional forms, this generality would preclude obtaining the quantitative results that are sought. Therefore, it is specified in linear functional form from the outset, thus allowing the use of a calibration method due to Dixit (1988).

The approach taken is to specify an $n$-firm oligopsony/oligopoly that acts as the counterfactual to the state trading enterprise. From the calibrated equations of demand and 
supply, the optimal quantity imported in the counterfactual can be calculated from the firstorder conditions. Then, by equating this quantity imported, as a function of the implicit tariff rate and of $n$, with the quantity imported by the STE, the tariff equivalence of the STE is obtained.

Consumer utility is assumed to be separable and linear in the numeraire good. Rice is assumed to be a differentiated product with domestically produced and imported rice being imperfect substitutes. The inverse demand functions for rice that are derived from the constrained maximisation of utility are given by:

$$
\begin{aligned}
& p_{h}=a_{1}-b_{1} Q_{h}-\gamma Q_{m} \\
& p_{m}=a_{2}-\gamma Q_{h}-b_{2} Q_{m}
\end{aligned}
$$

where: $p_{i}(i=h, m)$ is the consumer price of domestically-produced rice $(h)$ and imported rice (m); $Q_{i}(i=h, m)$ are the aggregate quantities of domestically-produced and imported rice consumed, respectively; and $\left(b_{1} b_{2}>\gamma^{2}\right){ }^{6}$

The inverse supply function for the domestically-procured rice is given by:

$$
p_{d}=f+k Q_{h}
$$

and for imported rice by:

$$
p_{w}=F+K Q_{m}
$$

In the small country case, where there is no potential for terms of trade effects in the purchase of imports, $K=0$. It what follows, it is assumed that Japan is a large country in the international rice market and that $K>0$.

\subsection{The Counterfactual}

The counterfactual is an $n$-firm oligopsony/oligopoly that is unconstrained in its import procurement. Let the representative private intermediary, subscripted by priv, have a profit function defined as the sum of profits made from procuring domestically-produced rice and profits made from importing rice. Any other costs are ignored. Because this $n$-firm oligopsony/oligopoly acts the counterfactual against which the tariff equivalence of the Food Agency is measured, the firm's profit function also needs to include a term that reflects this equivalence. Now, with imperfect competition and an upward sloping inverse import supply function, an ad valorem and a specific tariff are not equivalent. Because the border price of imports is a function of the tariff for $K>0$, it would make comparisons of tariff equivalence

\footnotetext{
${ }^{6}$ In reality, another source of supplies of rice to domestic consumers is the release from governmentheld stocks. However, because the model being specified here is a one-period model, the presence of stocks can be ignored by assuming no stock-change.

${ }^{7}$ If the government chose a minimum producer price as a way of assisting farmers' incomes, then $f$ would be that minimum price and $k$ would be zero.
} 
easier to interpret across different simulations if the tariff equivalence were specified in ad valorem form rather than in specific form. The alternative approach is to specify the tariff in specific form and then to calculate the ad valorem equivalence as the border price changes. The second of these approaches is used because, in section 4, the Food Agency's mark-up and the out-of-quota tariff are given in specific form.

The profit function of the representative firm in the counterfactual is defined as

$$
\pi_{\text {priv }}=\pi_{h}+\pi_{m}=\left(p_{h}-p_{d}\right) q_{\text {priv }, h}+\left(p_{m}-p_{w}-t^{e}\right) q_{\text {priv }, m}
$$

where: $\pi_{h}\left(\pi_{m}\right)$ is profit from buying and selling domestically-procured (imported) rice; and $t^{e}>0$ implies an import tax and $t^{e}<0$ an import subsidy. If $t^{e}=0$, then the STE is not trade distorting. Maximising this function with respect to the domestic quantity and the imported quantity procured, gives the first-order conditions for the representative firm

$$
\left[\begin{array}{cc}
\left(b_{1}+k\right)(n+1) & \gamma(n+1) \\
\gamma(n+1) & \left(b_{2}+K\right)(n+1)
\end{array}\right]\left[\begin{array}{c}
q_{p r i v, h} \\
q_{p r i v, m}
\end{array}\right]=\left[\begin{array}{c}
a_{1}-f \\
a_{2}-F-t^{e}
\end{array}\right]
$$

which, when aggregated over $n$ firms, gives the optimal aggregate quantities procured from each source

$$
\left[\begin{array}{c}
Q_{p r i v, h}^{*} \\
Q_{p r i v, m}^{*}
\end{array}\right]=\frac{n}{\Delta_{p r i v}}\left[\begin{array}{cc}
\left(b_{2}+K\right)(n+1) & -\gamma(n+1) \\
-\gamma(n+1) & \left(b_{1}+k\right)(n+1)
\end{array}\right]\left[\begin{array}{c}
a_{1}-f \\
a_{2}-F-t^{e}
\end{array}\right]
$$

where $\Delta_{\text {priv }}=(n+1)^{2}\left[\left(b_{1}+k\right)\left(b_{2}+K\right)-\gamma^{2}\right]$.

\subsection{The STE}

The STE differs from the counterfactual in two ways. First, it may pursue an objective that is not necessarily profit maximisation. Instead, it has to pursue one given to it by government as the means by which the latter achieves its objective in the rice sector. The second difference is that the STE may have exclusive rights in specific markets. For example, prior to 1995, the Japanese government, in increasing the incomes of rice producers, gave the Food Agency exclusive rights over the purchase and sale of domestically procured and imported rice. Thus, the objective function of the STE during this period (subscripted by SJ) can be written as a weighted sum of producer surplus and the STE's profits: ${ }^{8}$

$$
W_{S J}=\alpha P S+(1-\alpha)\left(\pi_{S J, h}+\pi_{S J, m}\right)
$$

where $0 \leq \alpha<1$ is the weight given to producer surplus (PS) and $(1-\alpha)$ is the weight given to total profits. ${ }^{9}$ Maximisation of this function with respect domestic procurement $\left(Q_{S J, h}\right)$ and import procurement ( $\left.Q_{S J, m}\right)$ gives the following first-order conditions

\footnotetext{
${ }^{8}$ It is assumed that consumers' interests were achieved by other instruments.

${ }^{9}$ The policy weight, $\alpha$, is defined on the semi-open interval because of the way it enters equation (9).
} 


$$
\left[\begin{array}{cc}
2 b_{1}(1-\alpha)+k(2-3 \alpha) & 2 \gamma(1-\alpha) \\
2 \gamma & 2\left(b_{2}+K\right)
\end{array}\right]\left[\begin{array}{c}
Q_{S J, h} \\
Q_{S J, m}
\end{array}\right]=\left[\begin{array}{c}
(1-\alpha)\left(a_{1}-f\right) \\
\left(a_{2}-F\right)
\end{array}\right]
$$

which, when solved, give the optimal quantities procured,

$$
\left[\begin{array}{c}
Q_{S J, h}^{*} \\
Q_{S J, m}^{*}
\end{array}\right]=\frac{1}{\Delta_{S J}}\left[\begin{array}{cc}
2\left(b_{2}+K\right) & -2 \gamma(1-\alpha) \\
-2 \gamma & 2 b_{1}(1-\alpha)+k(2-3 \alpha)
\end{array}\right]\left[\begin{array}{c}
(1-\alpha)\left(a_{1}-f\right) \\
\left(a_{2}-F\right)
\end{array}\right]
$$

where $\Delta_{S J}=\left[2 b_{1}(1-\alpha)+k(2-3 \alpha)\right]\left[2\left(b_{2}+K\right)\right]-4 \gamma^{2}(1-\alpha)$. Note that with $\alpha=0$ and $n=1$, the counterfactual and the STE are identical entities, because they have the same objective, and equations (7) and (10) give the same optimal quantities, as should be expected. The tariff equivalence of the STE is found by equating $Q_{p r i v, m}^{*}$ in equation (7) with $Q_{S J, m}^{*}$ in equation (10) and solving for $t^{e}$. An inspection of these two equations suggests that $t^{e} \neq 0$ and, therefore, that imports in these two market structures will differ. What is not obvious from this inspection is whether the tariff equivalence is positive or negative.

Between FY1995 and FY1998 inclusive, the STE lost its exclusive rights to procure in the domestic market and it played no role there, except for its control of the publicly-held storage stocks that existed to help implement the objective of rice self-sufficiency. With the loss of control over the domestic procurement, the STE could have no direct influence on producer surplus nor did it any longer earn profits from selling domestically-procured rice. Its objective function is now:

$$
W_{S M}=(1-\alpha) \pi_{m}
$$

from which the first-order condition is

$$
(1-\alpha)\left[a_{2}-F-\gamma Q_{p r i v, h}-2\left(b_{2}+K\right) Q_{S M, m}\right]=0
$$

With the private firms restricted to domestic procurement only, equation (5) is revised to redefine the representative firm's profit as

$$
\pi_{h}=\left(p_{h}-p_{d}\right) q_{h}
$$

the maximisation of which gives

$$
\left(a_{1}-f\right)-\left(b_{1}+k\right)(n+1) q_{p r i v, h}-\gamma Q_{S M, m}=0
$$

Note that there is now no term for the tariff equivalence in equation (14) because the private firms do not import. Aggregating equation (14) over $n$ and combining with equation (12), gives the following first-order conditions:

$$
\left[\begin{array}{cc}
\left(b_{1}+k\right)(n+1) & \gamma n \\
\gamma & 2\left(b_{2}+K\right)
\end{array}\right]\left[\begin{array}{c}
Q_{p r i v, h} \\
Q_{S M, m}
\end{array}\right]=\left[\begin{array}{c}
n\left(a_{1}-f\right) \\
\left(a_{2}-F\right)
\end{array}\right]
$$

the solution to which is 


$$
\left[\begin{array}{c}
Q_{p r i v, h}^{*} \\
Q_{S M ~}^{*}
\end{array}\right]=\frac{1}{\Delta_{S M}}\left[\begin{array}{cc}
2\left(b_{2}+K\right) & -\gamma n \\
-\gamma & \left(b_{1}+k\right)(n+1)
\end{array}\right]\left[\begin{array}{c}
n\left(a_{1}-f\right) \\
\left(a_{2}-F\right)
\end{array}\right]
$$

where $\Delta_{S M}=2\left(b_{1}+k\right)\left(b_{2}+K\right)(n+1)-n \gamma^{2}$. A comparison of equations (10) and (16) illustrates the effect of the change in exclusive rights on equilibrium quantities; and a comparison of each with equation (7) shows the difference in outcomes with the counterfactual.

\section{The Period Post-1998}

In section 3, the existence of the tariff quota has been ignored in order to study the effect of the extent of the exclusive rights enjoyed by the Food Agency on the equilibrium quantities and on the tariff equivalence of the Food Agency. In this section, the existence of the tariff quota, as described in section 2, is now recognised and brought into the model. This reality becomes difficult to specify because imports are procured partly by the Food Agency directly through the OMA with a variable mark-up, and partly by the Food Agency indirectly through private firms and the SBS system, also with a variable mark-up. There is also the complication in specifying the model because some private firms may confine their procurement to the domestic market only, others to the import market only, and yet others will procure in both, thereby engaging in third-degree price discrimination. In what follows, it is assumed for simplicity that all of the private firms procure in both markets. ${ }^{10}$

Under the OMA portion of the tariff quota, the mark-up is flexible but it can be no more than $¥ 292,000$ per tonne. What causes the Food Agency to choose one value over another is not obvious, i.e., the mark-up is endogenous. It may be that the size of the mark-up is dependent on the state of the domestic market supply and demand balance, including stocks. Under the SBS portion, the Food Agency chooses the tenders from private firms with the greatest mark-ups. The Cournot model with a representative firm (equation (6)) cannot accommodate this behaviour unless it is assumed that the firms have heterogeneous procurement prices. However, given the assumption that importing firms purchase from perfectly competitive export suppliers of a homogeneous product along a single import supply function (equation (4)), although a product that is differentiated from domestic rice, it is not feasible to assume different procurement prices. Therefore, it is not feasible to model these firms as having different marginal cost functions and, therefore, different mark-ups.

An alternative approach, and the one now pursued, is to treat the OMA part of the model as exogenous because of the WTO commitment. The OMA tariff quota is assumed to

\footnotetext{
${ }^{10}$ In practice, firms that wish to import rice through the SBS channel need to obtain approval from MAFF. For the specification of a model in which some private firms procure only in the domestic market while others are licensed to procure in both, see McCorriston and MacLaren (2010).
} 
be exactly filled with no out-of-quota imports and the Food Agency's mark-up is assumed exogenous. This description is consistent with the data used for calibration (see section 5). Under the SBS portion, imports are endogenous and they may or may not be constrained by the SBS portion of the tariff quota. Procurement in the domestic market will continue to be treated as endogenous with profit-maximising Cournot intermediaries.

The objective function of the representative firm is

$$
\pi_{\text {priv }}=\pi_{h}+\pi_{m}=\left(p_{h}-p_{d}\right) q_{\text {priv }, h}+\left(p_{m}-p_{w}-\mu_{S B S}\right) q_{\text {priv }, m}
$$

where $\mu_{S B S}$ is the mark-up tendered by private importers. It is assumed here to be exogenous for the reason already explained but, in practice, it is endogenous. Maximisation of equation (17) with respect to $q_{\text {priv, }}$ and $q_{\text {priv, } m}$ is constrained by the SBS quota. The Food Agency has an objective function but one that is not optimised. Instead, it is included only in order to complete the welfare accounting in the rice market. Its objective function is:

$$
W=582,200 \mu_{\text {OMA }}+100,000 \mu_{S B S}
$$

where: $\mu_{\text {OMA }} \leq 292,000$ is the mark-up charged by the Food Agency in yen per tonne imported as part of the OMA import regime.

Consolidating the representative firm's first-order conditions with the exogenous level of imports in the OMA regime, gives the following equilibrium conditions for the quantities procured:

$$
\left[\begin{array}{ccc}
\left(b_{1}+k\right)(n+1) & \gamma(n+1) & 0 \\
\gamma(n+1) & \left(b_{2}+K\right)(n+1) & 0 \\
0 & 0 & 1
\end{array}\right]\left[\begin{array}{c}
q_{\text {priv }, h} \\
q_{\text {priv }, m} \\
Q_{\text {OMA }}
\end{array}\right]=\left[\begin{array}{c}
\left(a_{1}-f\right) \\
\left(a_{2}-F-\mu_{S B S}\right) \\
582200
\end{array}\right]
$$

Aggregating over $n$ and solving gives:

$$
\left[\begin{array}{c}
Q_{\text {priv, } h}^{*} \\
Q_{\text {priv, } m}^{*} \\
Q_{O M A}^{*}
\end{array}\right]=\frac{1}{\Delta_{S Q}}\left[\begin{array}{ccc}
\left(b_{2}+K\right)(n+1) & -\gamma(n+1) & 0 \\
-\gamma(n+1) & \left(b_{1}+k\right)(n+1) & 0 \\
0 & 0 & \Delta
\end{array}\right]\left[\begin{array}{c}
n\left(a_{1}-f\right) \\
n\left(a_{2}-F-\mu_{S B S}\right) \\
582200
\end{array}\right]
$$

where $\Delta_{S Q}=(n+1)^{2}\left[\left(b_{2}+K\right)\left(b_{1}+k\right)-\gamma^{2}\right]$. If the solution for $Q_{p r i v, m}^{*}$ in equation (20) exceeds 100,000 , then imports per firm are set to $100,000 / n$ and the profit maximisation in equation (17) is constrained by the quota. 


\section{The Data ${ }^{11}$}

A calibration exercise was undertaken to determine the magnitude of the tariff equivalence of the STE in the period pre-FY 1995, and to provide some quantitative results for imports, domestic procurement and welfare in the period post-FY1999. This calibration exercise, based on Dixit (1988), required a set of data points and price elasticities in order to obtain estimates of the parameters in equations (1), (2), (3) and (4). The data are shown in Table 1, together with the elasticities and the calculated parameters.

The demand functions are defined at the wholesale level because of the difficulty of obtaining reliable consumer prices for imported rice. In practice, rice imported under OMA is stockpiled after importation and it is released at some later date for manufacturing purposes rather than directly as table rice for consumption. Given the static, one-period model being used, this refinement is not an issue because the monthly data that were used were aggregated to annual values.

The data on prices are as follows. The wholesale price of domestic-produced rice was taken from RSSSO with the 5 per cent consumption tax removed. The domestic producer price was taken from RSSSO. The wholesale price of imported within-quota rice was calculated as a weighted average of the prices of OMA, SBS and out-of-quota rice, these data coming from MAFF's summary of imported Rice SBS results. Out-of-quota import prices were obtained from Japan Customs' trade data as unit values. The world price was taken to be the Californian price of medium grain rice from the USDA.

The data on quantities are as follows. Import quantities are the sum of manufacturing-use OMA rice that has been released from stocks plus SBS imports plus outof-quota imports. The data source is MAFF auction results for minimum access rice and Japan Customs trade date for out-of-quota imports. Consumption of domestic rice is defined from domestic production less changes in stocks less exports. These data were taken from MAFF's Survey of Producers' Rice Inventories.

\section{[Table 1]}

\section{Results and Discussion}

The first objective in the paper is the evaluation of the assertion that importing STEs affect only the domestic market and not the international market. The results obtained from using equations (7) and (10) to solve for the tariff equivalence of the STE, with different numbers of firms in the counterfactual and with different policy weights, are given in Figure

\footnotetext{
${ }^{11}$ I am grateful to James Fell for allowing me to use his data, which are series of monthly data that he put together on prices and quantities, taking into account the discrepancy between a quantity imported in a particular month and the month in which that import shipment was released for consumption from the Food Agency's stocks.
} 
1. Because, in none of the cases is the tariff equivalence zero, but is substantially positive, it can be concluded that the STE is equivalent to a tariff. For the calibrated parameters used (see Table 1), the values range from 311 per cent to 3490 per cent depending upon the values of $n$ and $\alpha$. By implication, as $n$ increases, the welfare loss to exporters from the existence of the STE also increases.

The tariff equivalence is as increasing and concave function of the number of firms, as would be expected given the Cournot assumption, because quantities procured are an increasing function of the number of firms. The tariff equivalence is an increasing but convex function of the policy weight. The reason that the tariff equivalence appears to increase at an increasing rate with alpha is that imports are a decreasing and concave (from below) function of alpha. Although not shown in Figure 1, if in equation (4) $\mathrm{K}=0$, and the equations are recalibrated, the tariff equivalences remain positive, although smaller than the values shown in the Figure. For example, with $n=2$ and $\alpha=0.25$, the tariff equivalence is 148 per cent instead of 311 per cent. Therefore, even in the small country case, an importing STE that takes into account the welfare of domestic producers will act as a tariff.

\section{[Figure 1 here]}

The second objective is to evaluate the current import regime. Making use of equation (20) to determine the optimal quantities procured by the private firms in the current import regime, it was found that the SBS import quota was violated. Therefore, the quota constraint was applied and in-quota, SBS imports set to 100,000. The new specification is

$$
\left[\begin{array}{ccc}
(n+1)\left(b_{1}+k\right) & \gamma(n+1) & \gamma n \\
0 & 1 & 0 \\
0 & 0 & 1
\end{array}\right]\left[\begin{array}{c}
Q_{h} \\
Q_{S B S} \\
Q_{O M A}
\end{array}\right]=\left[\begin{array}{c}
n\left(a_{1}-f\right) \\
\bar{m}_{S B S} \\
\bar{m}_{\text {OMA }}
\end{array}\right]
$$

where: $\bar{m}_{S B S}$ is the SBS tariff quota of 100,000 tonnes and $\bar{m}_{\text {OMA }}$ is the OMA tariff quota of 582,200 tonnes. Social welfare was calculated as a function of the number of firms and compared with the situation that existed pre-1995 when there was no tariff quota in place, and it was assumed for that period that the STE was free to import whatever quantity maximised its objective function (equation (10)). The resulting difference in social welfare is shown in Figure 2. Clearly, the current regime is welfare enhancing compared with the STE-only regime that prevailed prior to 1995.

\section{[Figure 2 here]}

The model was re-specified further to recognise that private firms can import in excess of the SBS quota as long as they are prepared to pay the out-of-quota tariff. The respecified model is 


$$
\left[\begin{array}{cccc}
(n+1)\left(b_{1}+k\right) & \gamma(n+1) & \gamma n(n+1) & \gamma n \\
\gamma(n+1) & \gamma(n+1)\left(b_{2}+K\right) & b_{2}(n+1)+K & b_{2} n \\
0 & 0 & 1 & 0 \\
0 & 0 & 0 & 1
\end{array}\right]\left[\begin{array}{c}
Q_{h}^{*} \\
Q_{m}^{*} \\
Q_{S B S}^{*} \\
Q_{O M A}^{*}
\end{array}\right]=\left[\begin{array}{c}
n\left(a_{1}-f\right) \\
n\left(a_{2}-F-T-\mu_{\text {OMA }}\right) \\
\bar{m}_{\text {SBS }} \\
\bar{m}_{\text {OMA }}
\end{array}\right]
$$

where: $Q_{m}^{*}$ are out-of-quota imports; and $T$ is the out-of-quota specific tariff.

To investigate the possibility of out-of-quota imports and the out-of-quota tariff that would lead to such imports, values for the out-of-quota tariff were chosen and the out-ofquota quantity of imports calculated. It was found that when this tariff reached approximately $¥ 24 / \mathrm{kg}$, out-of-quota imports became zero. Therefore, the current out-of-quota tariff of $¥ 49 / \mathrm{kg}$ is indeed prohibitive. The values of social welfare for Japan and for the exporting countries were also calculated. The results for Japan are shown in Figure 3; the results for the exporting countries are in Figure 4.

\section{[Figure 3 here]}

The series labelled "Counterfactual with tariff" in Figure 3 is the welfare level achieved in Japan if the current tariff quota regime were replaced with an $n$-firm oligopoly/oligopoly that faced a specific tariff. Clearly, there are benefits from changing the method of restricting imports. The difference between the two series is accounted for by a combination of a different level of imports and the financial effects of the loss of mark-ups, the out-of-quota tariff revenue and the tariff revenue in the counterfactual in which the tariff quota does not restrict imports. It is calculated that the optimal tariff is approximately $¥ 130 / \mathrm{kg}$. In Figure 4, it is noticeable that the exporters are better off with the counterfactual and facing a simple tariff rather than the current complex arrangements involving the OMA and SBS allocations within the tariff quota.

\section{[Figure 4 here]}

It is concluded that the current out-of-quota tariff is excessive and that it leads to a welfare loss, which is compounded by the mark-ups applied to OMA and SBS imports within the tariff quota. It is also concluded that a much simpler institutional arrangement to restrict imports is available and it would lead to greater social welfare in both Japan and for exporters.

\section{Conclusions}

It was claimed early in the negotiations on agriculture in the WTO, which preceded the Doha Declaration, that importing STEs affect only the domestic market of the country in 
which the STE is found. ${ }^{12}$ The first objective in this paper was to evaluate the assertion that importing STE do not affect the international market. Using a calibrated model of an $n$-firm Cournot oligopoly/oligopoly as the counterfactual set of intermediaries, and using data for the Japanese rice market, it is concluded that an importing STE that takes domestic producer surplus into account in maximising its objective function, is equivalent to a tariff. Consequently, the STE does affect the international market and it does so even if the country is regarded as 'small' in the international market. The STE is shown to be equivalent to an import tax regardless of the size of $n$ and regardless of the weight placed by government on the welfare of domestic producers. In particular, the greater is the number of firms $(n)$ in the counterfactual, the greater is the tariff equivalence of the STE; and the greater the weight $(\alpha)$ placed on domestic producers, the greater the restriction of imports and the greater is the tariff equivalence of the STE and, as a consequence, the greater the welfare loss to exporters. Therefore, it can be concluded that importing STEs should be subject to discipline in the WTO.

A second objective was to investigate the welfare effect of the current import regime, i.e., the tariff quota. The model was specified to separate the OMA and SBS portions of the overall quota of 682,200 tonnes per annum. The case in which there are no out-of-quota imports was compared with the situation that existed pre-1995 and it was found that the current regime improved social welfare slightly compared with that in the earlier period. It was also found that the current out-of-quota tariff of $¥ 49 / \mathrm{kg}$ is prohibitive; even a tariff of $¥ 24 / \mathrm{kg}$ brings out-of-quota imports to zero. Therefore, the current, prohibitive out-of-quota tariff leads to a loss of welfare for both Japan and for exporters compared with a situation in which the out-of-quota would be set at a smaller amount. Moreover, the current use of the tariff quota generates a smaller level of social welfare than would be obtained through the unrestricted access to imports of an $n$-firm oligopsony/oligopoly.

There are number of caveats that need to be kept in mind in interpreting these results. First, the model used to simulate the various cases is of course a substantial simplification of the complex institutional arrangements that exist. Second, the domestic institutional arrangements were taken as given and were not modelled. Third, it was assumed that the Food Agency is equally as efficient in its procurement and distribution as are private firms. However, there is evidence from other countries to suggest that the unit costs of STEs are higher than those of commercial firms. Nevertheless, with these caveats in mind, it has been shown that there are substantial overall welfare losses in Japan from its import arrangements

\footnotetext{
${ }^{12}$ Because such STEs are no longer on the agenda for the agricultural negotiations taking place as part of the Doha Round, it could be that this claim was accepted by the negotiators as correct.
} 
for rice, which appear to be constructed to ensure self-sufficiency. The result in the paper provide an estimate of the opportunity cost of this policy.

\section{References}

Dixit, A.D., (1988) Optimal trade and industrial policies for the US automobile industry, in R.C. Feenstra (ed.), Empirical Methods for International Trade, Cambridge MA: MIT Press, pp. 141-165.

FAO (2010) International Trade in Rice, Recent Developments and Prospects, Rome. Available at http://www.fao.org/es/esc/en/15/70/81/highlight_79.html (accessed June 2010).

Fell, James (2009) The Welfare Cost of Japanese Rice Policy with Home-Good Preference and Imperfect Import Substitution, Economics Honours Research Essay, Department of Economics, The University of Melbourne.

Fujiki, H. (2000). Japanese Rice Market Liberalization: a Competitive Equilibrium Approach, The Japanese Economic Review 51(4):492-518.

Honma, M. and T. Hayami (2009) Distortions to agricultural incentives in Korea, Japan and Taiwan, in K. Anderson (ed.), Distortions to Agricultural Incentives: A Global Perspective 1955-2007, London: Palgrave Macmillan, and Washington: World Bank, pp. 67-114.

Japan Customs (Various) Trade Statistics of Japan. Available at http://www.customs.go.jp/index_e.htm (accessed May 2009).

Lahiri, S. and Y. Ono (1999) Optimal tariffs in the presence of middlemen, Canadian Journal of Economics 32: 55-70.

Lloyd, P.J. (1982) State trading and the theory of international trade, in M.M. Kostecki (ed.), State Trading International Markets, New York: St. Martin's Press, pp. 117-14.

MAFF (Various) MA Ippan Yunyuu Mai Nyuusatsu Kekka no Gaiyou (Summary of Ordinary MA Imported Rice Tender Results).

__ Seisansha no Beikoku Genzaidaka nado Chousa (Survey of Producers’ Rice Inventories and Other Items).

__ Yunyuu Mai ni Kakaru SBS no Kekka no Gaiyou (Summary of Imported Rice SBS Results).

McCorriston, S. and D. MacLaren (2005) The trade distorting effect of state trading enterprises in importing countries, European Economic Review 49: 1693-1715. 
McCorriston, S. and D. MacLaren (2008) State Trading Enterprises as an Impediment to Improved Market Access: The Case of the Korean Rice Market, Review of International Economics 16(3): 431-443.

McCorriston, S. and D. MacLaren (2010) The Trade and Welfare Effects of State Trading in China with Reference to COFCO, The World Economy 44: 615-32.

OECD (2001) State Trading Enterprises in Agriculture, Paris: Organisation for Economic Cooperation and Development.

OECD (2009a) Producer and Consumer Support Estimates, OECD Database 1986-2008, http://www.oecd.org/document/59/0,3343,en_2649_33797_39551355_1_1_1_37401, 00.html.

OECD (2009b) Evaluation of Agricultural Policy Reform in Japan, Paris: Organisation for Economic Co-operation and Development.

OECD (2009c) Agricultural Policies in OECD Countries: Monitoring and Evaluation, Paris.

RSSSO (Various) Kome no Oroshi Uri Kakaku no Suii (Movement in the Wholesale Price of Rice) Rice Stable Supply Support Organisation. Available from URL:

http://www.komenet.jp/komedata/ (accessed September 2009).

USDA (Various) California medium-grain \#1 price in Rice Outlook Monthly Tables.

Available from URL: http://www.ers.usda.gov/Briefing/Rice/data.htm (accessed July 2009.

WTO (1995) The Results of the Uruguay Round of Multilateral Trade Negotiations: The Legal Texts, Geneva: The World Trade Organization.

WTO (2000) Summary Report on the Third Meeting of the Special Session held on 28-29 September 2000, Note by the Secretariat, G/AG/NG/R/3, 10 November, Geneva: The World Trade Organization.

WTO (2008) Revised Draft Modalities for Agriculture, TN/AG/W/4/Rev.4, 6 December, Geneva: World Trade Organization. 
Table 1: Data and Calibrated Parameters

\begin{tabular}{ll}
\hline Data and elasticities & Value \\
\hline (1) Wholesale price of imported rice (¥/tonne) & 123,331 \\
(2) Wholesale price of domestic rice (¥/tonne) & 341,262 \\
(3) Domestic producer price of rice (¥/tonne) & 207,513 \\
(4) Border price of imported rice (¥/tonne) & 58,834 \\
(5) Sales of domestically produced rice (tonnes) & $6,345,788$ \\
(6) Sales of imported rice (tonnes) & 682,000 \\
(7) Export supply elasticity & 1 \\
(8) Domestic supply elasticity & 0.3 \\
(9) Demand elasticity & -0.25 \\
(10) Elasticity of substitution & 5 \\
(11) OMA mark-up (¥/tonne) & 90,000 \\
(12) SBS mark-up (¥/tonne) & 140,000
\end{tabular}

$\begin{array}{cc}\text { Calibrated parameters } & \text { Value } \\ b_{1} & 0.2087 \\ b_{2} & 0.1663 \\ \gamma & 0.0599 \\ a_{1} & 1,706,311.67 \\ a_{2} & 616,653.58 \\ k & 0.1090 \\ f & -484,197.53 \\ K & 0.0863 \\ F & 0.0000\end{array}$

Source: $\quad$ (1) MAFF's Summary of Imported Rice SBS Results; (2) RSSSO; (3) RSSSO; (4) USDA; (5) MAFF's Survey of Producers' Rice Inventories and Others; (6) MAFF auction results for MA rice; (7) a chosen value to ensure a 'large' country effect; (8) Fujiki (2000); (9) a chosen value; (10) a chosen value; (11) calculated from SBS purchase and sale prices (mark-ups by tender are not published); (12) OMA mark-ups are not published but were estimated from the difference between MAFF's procurement price and its selling price of rice for processing. 
Figure 1: Tariff Equivalence of the STE for the Period Pre-1995

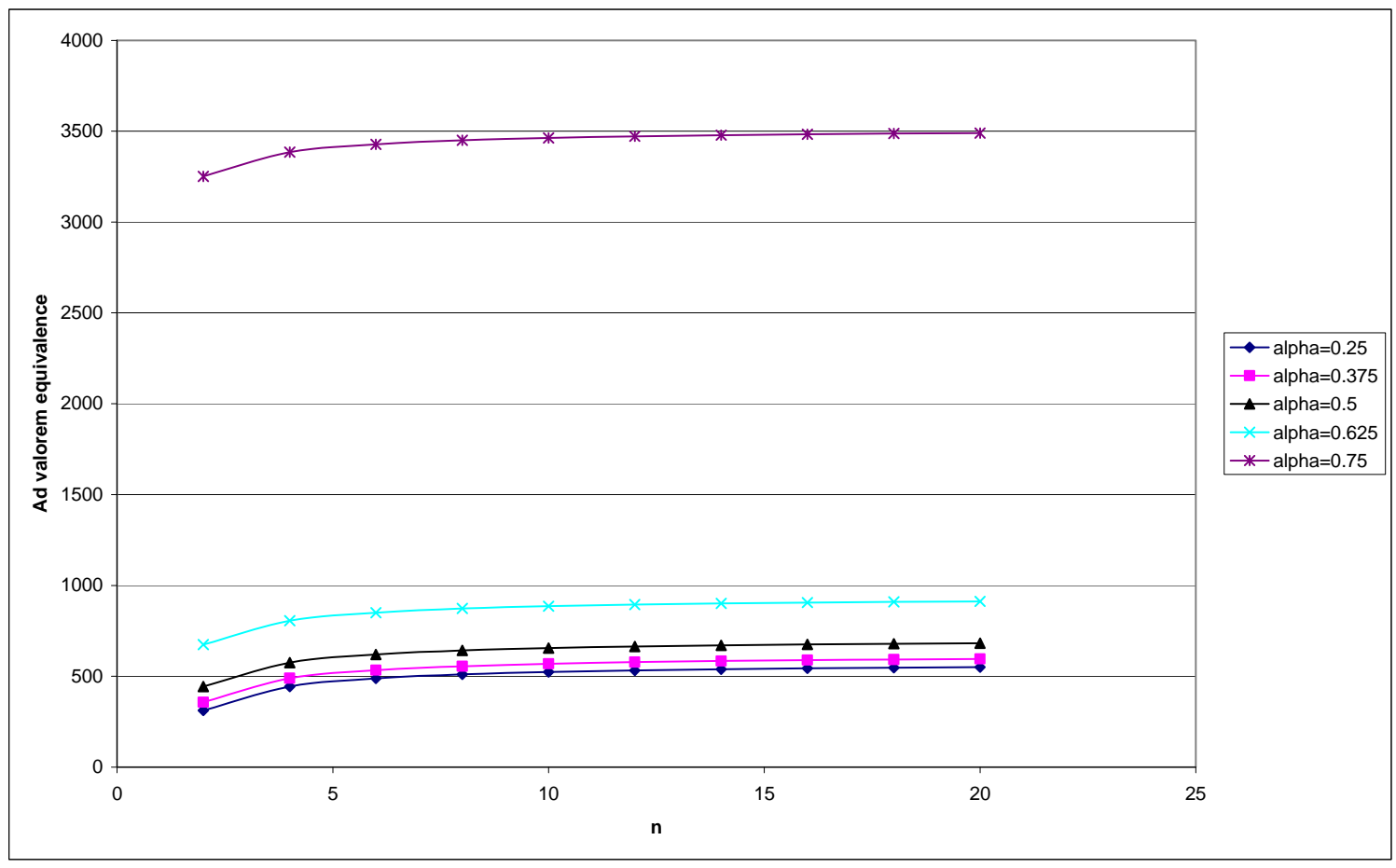


Figure 2: Social Welfare Pre-1995 and Post-1998

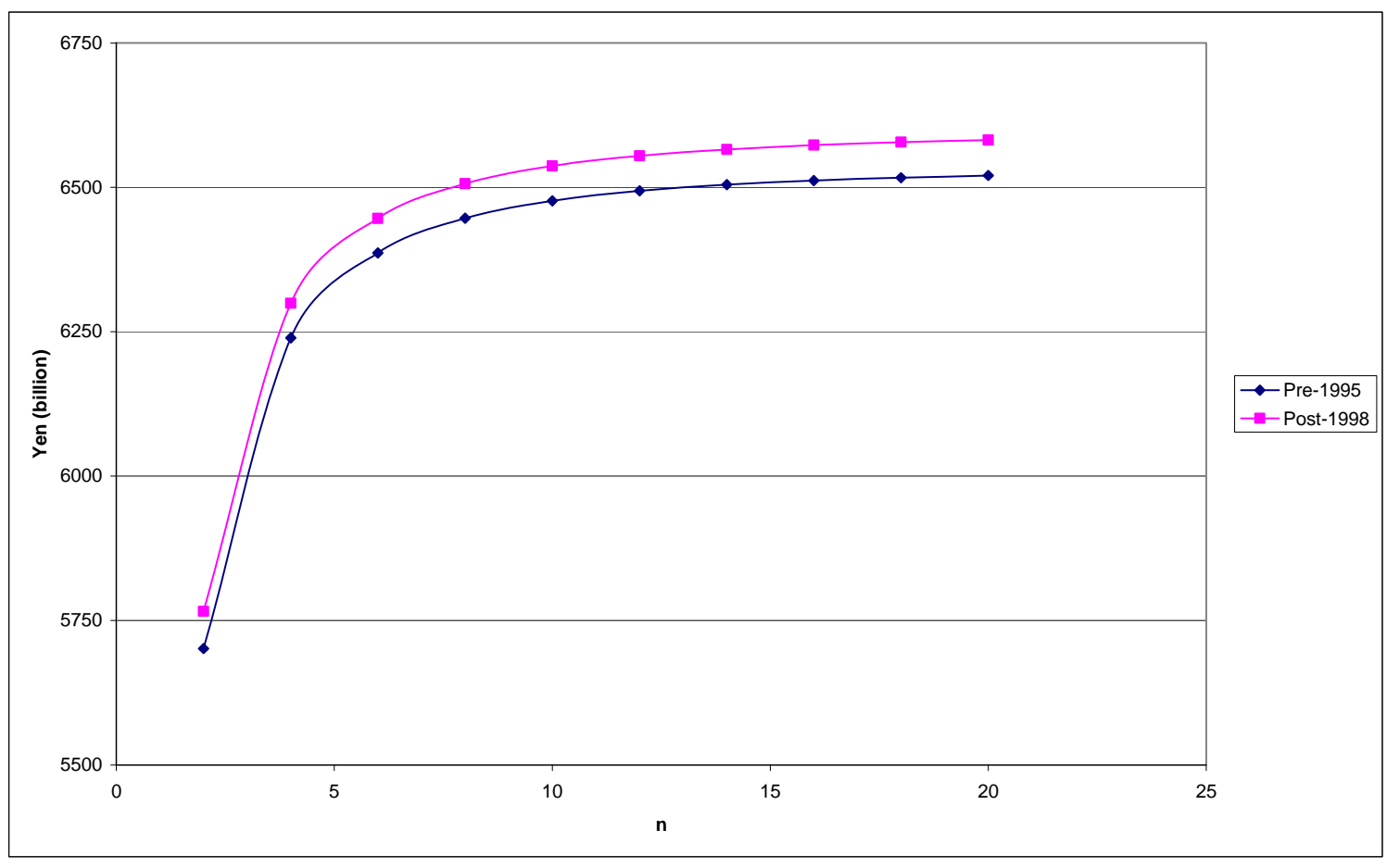


Figure 3: Social Welfare in Japan

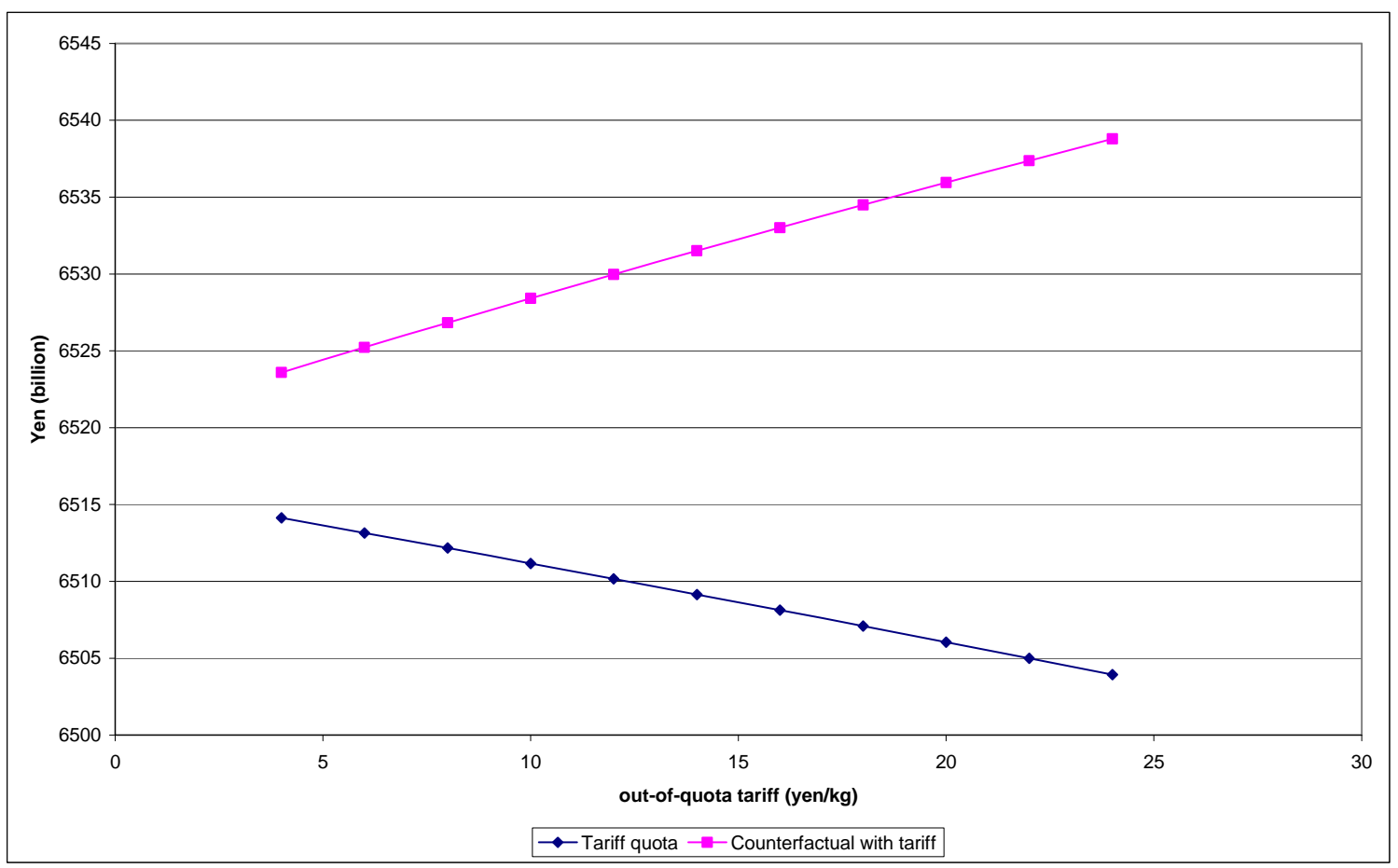

Note: $\quad$ These results have been generated using $n=20$.

For the series labelled "Tariff quota", the tariff on the horizontal axis is the outof-quota specific tariff. For the series labelled "Counterfactual with tariff", the horizontal axis is the simple tariff and not the out-of-quota tariff. 
Figure 4: Social Welfare of Exporters

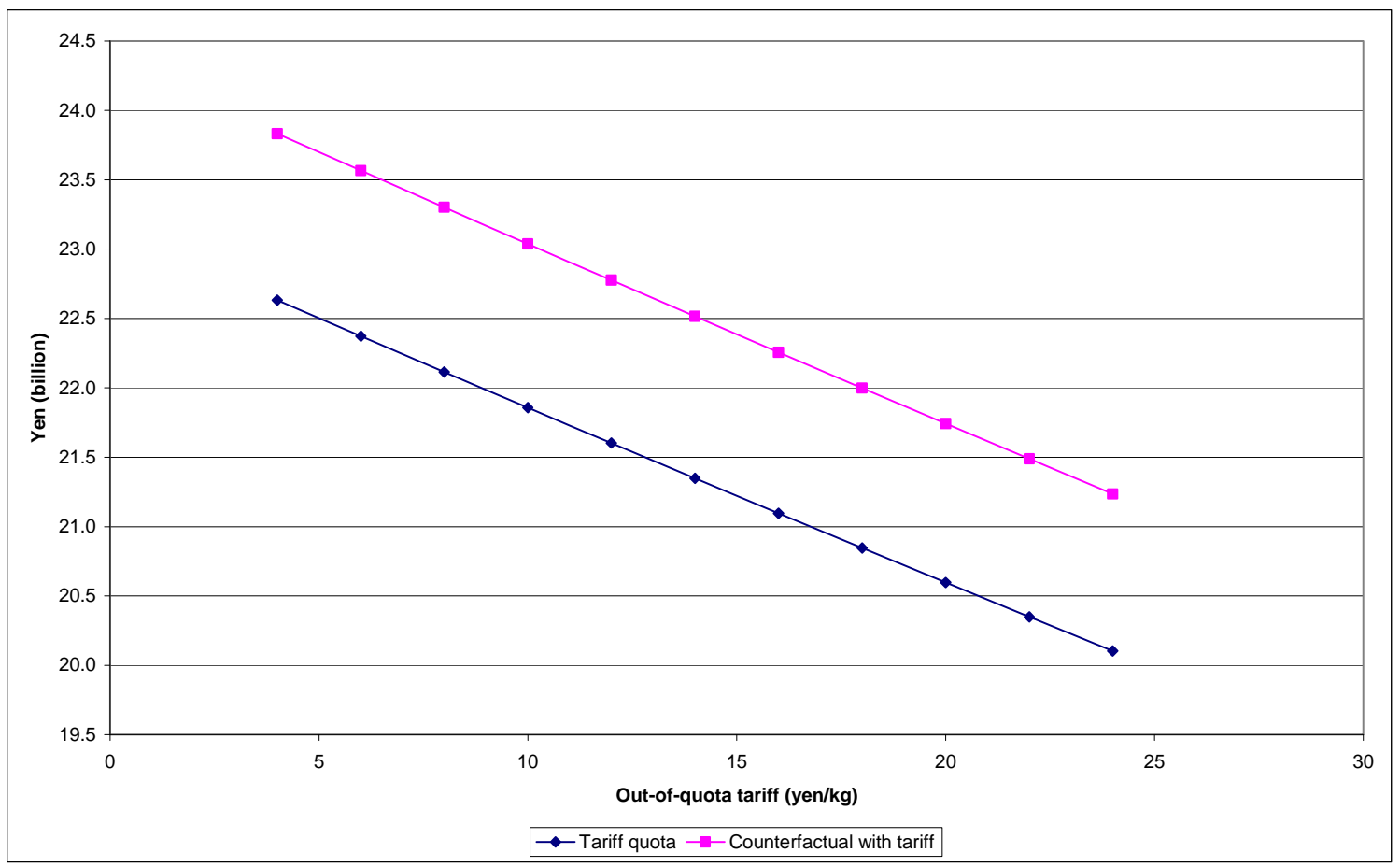

Note: $\quad$ These results have been generated using $n=20$.

For the series labelled "Tariff quota", the tariff on the horizontal axis is the outof-quota specific tariff. For the series labelled "Counterfactual with tariff", the horizontal axis is the simple tariff and not the out-of-quota tariff. 